\title{
Glycosylation of Hemoglobin in Normal and Diabetic Mothers and their Fetuses
}

\author{
W. PATRICK ZELLER, JOHN B. SUSA, JOHN A. WIDNESS, HERBERT C. SCHWARTZ, AND \\ ROBERT SCHWARTZ
}

Section of Pediatrics, Brown University Program in Medicine; Division of Pediatric Metabolism and Nutrition, Rhode Island Hospital; and the Departments of Pediatrics, Women and Infants Hospital of Rhode Island Providence, Rhode Island and Stanford University, Stanford, California, USA

\begin{abstract}
Summary
The magnitude of the glycosylated hemoglobin $(\mathrm{G} \mathrm{Hb})$ in 17 control and in 12 insulin-dependent diabetic mothers and their infants was measured using a thiobarbituric acid (TBA) colorimetric method. The maternal $\mathrm{G} H \mathrm{Hb}$ values were $12.3 \pm 3.1$ (mean \pm S.D.) nmoles fructose equivalents per $\mathrm{mg}$ of $\mathrm{Hb}(\mathrm{nM} \mathrm{FE} / \mathrm{mg}$ $\mathrm{Hb}$ ) for the control and $14.8 \pm 3.1$ for the insulin-dependent groups $(P<0.05)$. In contrast, the $G$ Hb values of infants of control and insulin-dependent diabetic mothers were not significantly different. The $\mathrm{G} \mathbf{~ H b}$ values for both groups of infants were approximately 60\% of their mothers' values: $\mathbf{7 . 6} \pm \mathbf{2 . 5}$ for the control infants and $8.3 \pm 1.5$ for the infants of insulin-dependent diabetics (IDMs) ( $P$ $<0.001$ compared to the mothers). A significant correlation was found between maternal and infant $\mathrm{G} \mathrm{Hb}(n=29, r=0.64, P<$ 0.001).

Additional umbilical blood hemoglobin solutions and corresponding chromatographically purified fetal hemoglobin fractions, including $\mathrm{Hb} \mathrm{F}_{\mathrm{I}}$ acetylated, $\mathrm{Hb} \mathrm{F}_{\mathrm{O}}$ nonacetylated, and $\mathrm{F}_{\mathrm{I}_{\alpha}}$ glycosylated, from three infant groups: controls, gestational diabetics and insulin-dependent mothers, were analyzed for total glycosylation by the TBA method. There were no significant differences in the degree of glycosylation between cord blood hemoglobin solutions and the chromatographically separated fetal hemoglobins. In view of these data it is unlikely that analysis of umbilical blood glycosylation by currently available techniques would distinguish normal infants from infants of controlled diabetic mothers or those with previously undiagnosed gestational diabetes.

High performance liquid chromatography was also used on maternal hemoglobin solutions to determine the total fast fractions (Hb $A_{I}$ ): $H b A_{I_{a+b}}$ and $H b A_{I_{c}}$. The maternal $A_{I}$ values were 7.49 $\pm 0.35 \%$ of total $\mathrm{Hb}$ for the controls and $10.1 \pm 1.38 \%$ for the diabetics $(P<0.001)$. Hb $A_{I}$, as measured by high performance liquid chromatography, correlated linearly with total glycosylation by the TBA method in control $(P<0.001)$ and diabetic $(P<0.05)$ mothers. Maternal glycohemoglobin determinations are preferable to cord blood determinations in assessing glucose control before delivery.
\end{abstract}

\section{Abbreviations}

$\mathrm{G} \mathrm{Hb}$, glycosylated hemoglobin

$\mathrm{Hb}$, hemoglobin

IDM, infants of insulin-dependent diabetic mothers

IGDM, infants of gestational diabetic mothers

TBA, thiobarbituric acid

Glycosylated hemoglobin $(\mathrm{G} \mathrm{Hb})$ has achieved importance in diabetes because of its implications for further evaluation of chronic glucose control as well as for possible structural alterations of other proteins, which may be associated with long-term diabetic complications (18). The glycosylation is a nonenzymatic, post- translational event in which glucose is condensed through a twostep reaction resulting in a stable ketoamine linkage mainly at the $\mathrm{N}$-terminal amino groups of the beta chain of the adult hemoglobin molecule (10). Several minor adult hemoglobins, which comprise fast $\mathrm{Hb}$ or $\mathrm{Hb} \mathrm{A}_{\mathrm{I}}$ and include $\mathrm{A}_{\mathrm{I}_{\mathrm{a}}}, \mathrm{A}_{\mathrm{I}_{\mathrm{u}}, \mathrm{A}_{\mathrm{I}}}, \mathrm{A}_{\mathrm{I}_{\mathrm{b}}}$ and $\mathrm{A}_{\mathrm{I}}$, may be separated by cation resin chromatography and account for $6-8 \%$ of normal total adult hemoglobin (12). These are modified by different adducts; $A_{I_{c}}$, which is the major fast $\mathrm{Hb}$, has glucose as its adduct. The $\mathrm{Hb} \mathrm{A}_{\mathrm{I}_{\mathrm{c}}}$ level correlates with the plasma glucose concentration over the prior 4-8 wk (11).

Posttranslational modifications of fetal hemoglobin $\left(\alpha_{2} \gamma_{2}\right)$ include both acetylation $\left(\mathrm{F}_{\mathrm{I}}\right)$ and glycosylation $\left(\mathrm{F}_{\mathrm{I}_{\mathrm{a}}}\right)$. Hemoglobin $F_{I}$ is acetylated on the $N$-terminal glycine of the $\gamma$ chain and usually comprises $15-20 \%$ of the total fetal hemoglobin $(\mathrm{Hb} \mathrm{F})$ at term (20). The majority of $\mathrm{Hb} \mathrm{F}(80-85 \%)$ is nonacetylated $\left(\mathrm{F}_{\mathrm{O}}\right)$.

Abraham et al. (1-4) have characterized the minor fetal hemoglobins. Their results indicate that $\mathrm{Hb} \mathrm{F}_{\mathrm{I}_{\mathrm{al}}}, \mathrm{Hb} \mathrm{F}_{\mathrm{I}_{\mathrm{a} 2}}$, and $\mathrm{Hb} \mathrm{F}_{\mathrm{I}_{\mathrm{c}}}$ have been formed by the modification of $\gamma$ chains of $\mathrm{Hb} \mathrm{F}_{\mathrm{O}}$ by reacting with fructose-1,6- $\mathrm{P}_{2}$, glucose-6-P and glucose, respectively. These minor fetal hemoglobins are analogous to the glycosylated minor adult hemoglobins $A_{I_{a 1}}, A_{x_{k 2}}$, and $A_{I_{r}}(12)$.

Because the minor adult hemoglobins co-elute with the fetal hemoglobins by cation exchange chromatography (19), they have been difficult to measure in newborn blood. We attempted previously to circumvent this problem by first isolating the total $\mathrm{Hb}$ $\mathrm{F}$ fraction from adult hemoglobin $\left(\mathrm{A}_{\mathrm{O}}\right)$ chromatographically and then analyzing the $\mathrm{Hb} \mathrm{F}$ fraction by isoelectric focusing and DEAE cellulose chromatography (17). We were not able to demonstrate any difference in acetylation or glycosylation occurring in infants of normal, gestational diabetic or insulin-dependent diabetic women. But Fitzgerald and Cauchi (8) were able to measure the glycosylated hemoglobins in neonatal blood using isoelectric focusing with the addition of specific modifying ampholine spacers. Preliminary data failed, however, to show an increase in glycohemoglobin in infants of diabetic mothers.

The present investigation was undertaken to determine if there was an association between glycosylated hemoglobin in mothers and fetuses at delivery as measured by the thiobarbituric acid (TBA) colorimetric chemical assay, which directly measures the ketoamine linkage. Infant-mother paired samples from control and insulin-dependent diabetic pregnancies were studied. In addition, purified $\mathrm{Hb} \mathrm{F}$ solutions, which were separated from adult $\mathrm{Hb} \mathrm{A}_{\mathrm{o}}$ from infants of normal, of gestational diabetic (IGDMs) and of insulin-dependent diabetic mothers (IDMs) were analyzed by the TBA technique for comparison with cord whole blood $\mathrm{Hb}$ solutions.

\section{SUBJECTS, MATERIALS AND METHODS}

Seventeen control women who had no risk factors for glucose intolerance (23), and 12 insulin-dependent diabetic subjects (White's Class A-D) had blood obtained at elective cesarean 
section. The mean gestational ages were $39.5 \pm 1.3 \mathrm{wk}$ and 36.0 $\pm 2.5 \mathrm{wk}$, respectively. The mean infant birth weights were 3.30 $\pm 0.40 \mathrm{~kg}$ for the controls and $3.13 \pm 0.60 \mathrm{~kg}$ for the IDMs. The mean infant birth weight ratios [ratio was determined by comparison of actual weight to the $50 \%$ value for gestational age of the infants (23)] were $0.98 \pm 0.12$ for the controls and $1.15 \pm 0.18$ for the diabetics. In addition, stored blood from other groups of previously studied subjects (17) (infants of controls, IGDMs and IDMs), along with the chromatographically eluted fractions $\mathrm{Hb}$

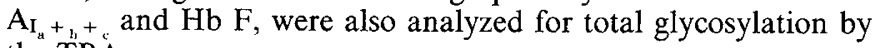
the TBA assay.

Whole blood samples were collected with informed consent in both Providence and Palo Alto. Although fetal samples were always drawn at the time of cesarean section, fasting (some mothers were receiving dextrose intravenously) maternal samples were all drawn within $4 \mathrm{~h}$ of delivery. Red cells and plasma were separated. Plasma samples were analyzed for glucose by a glucose oxidase technique with a Yellow Springs Instrument glucose analyzer $23 \mathrm{~A}$. Hemoglobin solutions were prepared by a standard technique as previously reported (16) and, when not analyzed immediately, were frozen at $-70^{\circ} \mathrm{C}$. Some of the pooled fetal hemoglobin solutions had been stored at both $-4^{\circ} \mathrm{C}$ and $-25^{\circ} \mathrm{C}$. Storage of frozen hemoglobin solutions has been shown by Pecoraro et al. (14) not to affect $\mathrm{G} \mathrm{Hb}$ levels even after prolonged storage.

The hemoglobin $\mathrm{F}$ solutions from cord blood were obtained by chromatography in Biorex 70 macrocolumns with two specific phosphate buffer concentrations and $\mathrm{pHs}$ (17). The efficiency of this separation was demonstrated by the absence of the $A_{0}$ peak determined by high performance liquid chromatography before TBA analysis. A modified high performance liquid chromatographic technique (22) was used selectively to quantify minor hemoglobins $\mathrm{Hb} \mathrm{A}_{\mathrm{I}_{\mathrm{a}+b}}$ and $\mathrm{Hb} \mathrm{A}_{\mathrm{I}_{\mathrm{e}}}$, and adult $\mathrm{Hb} \mathrm{A}_{O}$ in maternal samples and to separate fetal hemoglobin solutions into three fractions, $F_{I}, F_{O}$, and $A_{O}$. Dialysis was carried out as previously described (22).

The TBA colorimetric reaction was carried out by utilizing the reaction times, temperatures, and quantity of hemoglobin of $\mathrm{Pe}$ coraro et al (14). But, the reagents' concentrations and volumes were as follows: $10 \mathrm{mg}$ hemoglobin was diluted in triplicate to 400 $\mu \mathrm{l}$ with sterile water and $200 \mu \mathrm{l}$ of $0.7 \mathrm{~N}$ oxalic acid was added for the 4 -h acid hydrolysis at $100^{\circ} \mathrm{C}$. Then $200 \mu \mathrm{l}$ of $40 \%$ trichloroacetic acid was used for protein precipitation and $500 \mu \mathrm{l}$ of the supernatant was taken to obtain the initial optical density reading at $443 \mathrm{~nm}$. To this supernate, $500 \mu 10.0125 \mathrm{~N}$ TBA was added and samples incubated further at $37^{\circ} \mathrm{C}$. The change in absorbance at $443 \mathrm{~nm}$ was used to determine the nmoles of fructose equivalents from a standard curve.

Because the TBA method is nonstoichiometric, a series of five fructose standards at concentrations from $0-400 \mathrm{nM} / \mathrm{ml}$ were run with each series of unknowns. The fructose standards, however, followed Beer's Law. All standards and unknowns were determined in triplicate. Results were expressed as nmoles of fructose equivalents per $\mathrm{mg}$ hemoglobin $(\mathrm{nM} / \mathrm{mg} \mathrm{Hb}$ ). The coefficient of variation of the standards was $\pm 10 \%$, whereas on a single adult hemoglobin solution analyzed over a 7 -month period in triplicate $(n=21)$ it was $\pm 15.9 \%$. This large variation may be attributed in part to a number of substances in protein free, acid hydrolyzed extracts of hemolysate that form colored complexes with thiobarbituric acid.' Both coefficients of variation are greater than that obtained on adult diabetics studied with the high performance liquid chromatographic technique $( \pm 6.6 \%)$. There was also no difference in $\mathrm{nM} \mathrm{FE} / \mathrm{mg} \mathrm{Hb}$ determined after overnight dialysis in this same adult hemoglobin solution.

Statistical analysis included Student's $t$ test for paired and unpaired samples, as well as linear regression analysis.

\section{RESULTS}

Total fast maternal hemoglobin $\left(\mathrm{Hb} \mathrm{A}_{\mathrm{I}}\right.$ ), which includes fractions $\mathrm{Hb} \mathrm{A}_{\mathrm{I}_{\mathrm{i}+b}}$ and $\mathrm{A}_{\mathrm{I}_{\mathrm{c}}}$, as determined by high performance liquid chromatography, and the amount of glycosylation by the TBA chemical method are listed in Table 1. Dialyzed $\mathrm{Hb} \mathrm{A}_{\mathrm{I}}$ was elevated in the diabetic mothers: $7.10 \pm 0.96 \%(n=10)$ compared to $5.1 \pm 0.42 \%(n=14)$ in the controls $(P<0.001)$. Maternal Hb $\mathrm{A}_{\mathrm{I}}$, a well-known indicator of glucose homeostasis over the prior 4-8 wk, was found to correlate significantly with maternal $\mathrm{G} \mathrm{Hb}$ in control mothers $(r=0.69, P<0.002)$, insulin-dependent diabetic mothers $(r=0.58, P<0.05)$ and in the combined group $(r=0.58, P<0.001)$. In addition, maternal $\mathrm{Hb} \mathrm{A}_{\mathbf{I}_{c}}$ correlated with maternal G $\mathrm{Hb}$ for the combined group $(r=0.54, P<0.002)$.

Figure 1 shows $\mathrm{G} \mathrm{Hb}$ data for mother-infant pairs grouped as control and insulin-dependent mothers. The infant $\mathrm{G} \mathrm{Hb}$ was significantly lower (approximately 40\%) than the maternal sample $(P<0.001)$. The maternal $\mathrm{G} \mathrm{Hb}$ was significantly greater in the diabetic group compared to the controls $(P<0.05)$; however, there was no detectable difference in $\mathrm{G} \mathrm{Hb}$ between control infants and IDMs.

When the mother-infant $\mathrm{G} \mathrm{Hb}$ concentrations were analyzed by linear regression (Fig. 2), a significant correlation was found between maternal and infant $\mathrm{G} \mathrm{Hb}(r=0.64, P<0.001)$. Infant $\mathrm{G} \mathrm{Hb}$ concentration was related to infant birth weight ratio $(n=$ $29, r=0.43, P<0.02$ ) but not with birth weight per se.

Umbilical vein plasma glucose concentration was variable in both groups because some mothers received intravenous glucose: controls, $85.2 \pm 51.5 \mathrm{mg} / \mathrm{dl}$ and IDMs, $142 \pm 81 \mathrm{mg} / \mathrm{dl}$. Although these are significantly different $(P<0.03)$, no regression was evident when plasma glucose concentration was related to infant $\mathrm{G} \mathrm{Hb}$, although maternal $\mathrm{Hb} \mathrm{A}_{\mathrm{I}_{c}}$ was related $(P<0.005)$.

The degree of glycosylation of hemoglobin in cord blood hemolysate and in the purified fetal hemoglobin from that hemolysate was determined by the TBA method. There was no significant $G$ $\mathrm{Hb}$ difference between cord blood hemoglobin solutions and their corresponding fetal $\mathrm{Hb} \mathrm{F}$ solutions in infants of control, diabetic, or gestationally diabetic mothers by either paired or unpaired $t$ test. On paired analysis $(n=12)$ total $\mathrm{G} \mathrm{Hb}$ was $4.92 \pm 1.27$ compared to the $\mathrm{F}$ solution with $5.48 \pm 1.0$ nmoles $\mathrm{FE} / \mathrm{mg} \mathrm{Hb}(P$ $=0.73)$; unpaired analysis; total $(n=30) 5.2 \pm 1.5$ versus $\mathrm{F}$ solution $(n=15) 5.7 \pm 1.1$.

\section{DISCUSSION}

Hemoglobin glycosylation in the newborn correlated significantly with that of the mother in the combined group of control and diabetic subjects. This was not unexpected because fetal plasma glucose concentration tracks maternal glucose concentration (6); therefore, hemoglobin solutions prepared from cord blood may be used to assess fetal glycosylation. The total glycosylation of hemoglobin in the newborn was, however, only approximately $60 \%$ of the maternal value. The full explanation for this $40 \%$ reduction in fetal glycosylation is not yet known.

Minor adult hemoglobins have been difficult to distinguish from the fetal hemoglobins by the cation resin chromatographic techniques. In in vitro studies, Spicer et al. (19) found fetal hemoglobin after incubation with glucose to have an increase in the "apparent" acetylated $\mathrm{F}_{\mathrm{I}}$. Schwartz et al. (17) circumvented the co-elution problems by utilizing isoelectric focusing and ion exchange chromatography using DEAE cellulose, which allowed separation of minor hemoglobins in the precence of $\mathrm{Hb} \mathrm{F}$; however, they were not able to demonstrate any difference in acetylation or glycosylation occurring in the infants of control, IGDMs or IDMs. In contrast, Fadel et al. (7) have reported that the \% of minor hemoglobin $F_{I_{c}}$ shown to be a mixture of acetylated and glycosylated $\mathrm{Hb} \mathrm{F}$ is significantly elevated in infants of diabetic mothers. They also found that the ratios of $\mathrm{Hb} \mathrm{F}_{\mathrm{Y}} / \mathrm{Hb} \mathrm{F}$ and $\mathrm{Hb}$ $\mathrm{A}_{\mathrm{I}} / \mathrm{Hb} \mathrm{A}$ were elevated, but no pure $\mathrm{Hb} \mathrm{A}_{I_{\mathrm{I}}}$ was identified in fetal blood by these investigators; thus, these differences may only be detectable by highly specific techniques.

Caangay et al. (5) have previously noted in a preliminary communication that the maternal to cord ratio of glycohemoglobin (measured by TBA) averaged 1.3 in controls and 1.6 in diabetics. They found no difference between infants of normal and of 
Table 1. High performance liquid chromatography and thiobarbituric acid chemical determinations of paired maternal and fetal hemoglobin solutions

\begin{tabular}{|c|c|c|c|c|c|}
\hline \multirow[b]{2}{*}{ Subjects } & \multirow[b]{2}{*}{$\mathrm{n}$} & \multicolumn{3}{|c|}{$\%$ of total hemoglobin } & \multirow{2}{*}{$\begin{array}{l}\text { Glycosylated hemoglobin } \\
\text { (nM FE/mg Hb) }\end{array}$} \\
\hline & & $\mathrm{Hb} \mathrm{A} \mathrm{A}_{\mathrm{I}_{\mathrm{a}+\mathrm{h}}}$ & $\mathrm{Hb} \mathrm{A}_{\mathrm{I}_{c}}$ & $\mathrm{Hb} \mathrm{A}_{\mathrm{I}}$ & \\
\hline \multicolumn{6}{|l|}{ Mothers } \\
\hline Controls & 17 & $2.10 \pm 0.16^{1}$ & $5.39 \pm 0.31$ & $7.49 \pm 0.35$ & $12.3 \pm 3.1$ \\
\hline \multirow[t]{2}{*}{ Diabetics } & 12 & $2.16 \pm 0.19$ & $7.96 \pm 1.23^{3}$ & $10.1 \pm 1.38^{4}$ & $14.8 \pm 3.1^{3}$ \\
\hline & & $\mathrm{Hb} \mathrm{F}$ & $\mathrm{Hb} \mathrm{F}_{\mathrm{O}}$ & $F_{\text {total }}$ & Glycosylated hemoglobin \\
\hline \multicolumn{6}{|l|}{ Infants } \\
\hline Controls & 17 & $12.9 \pm 1.2$ & $71.5 \pm 5.4$ & $84.4 \pm 5.9$ & $7.5 \pm 2.5^{5}$ \\
\hline IDMs & 12 & $14.0 \pm 2.1$ & $75.9 \pm 2.0$ & $89.3 \pm 3.3^{2}$ & $8.3 \pm 1.5^{5}$ \\
\hline
\end{tabular}

${ }^{1}$ Mean \pm S.D.

${ }^{2} P<0.02$.

${ }^{3} P<0.05$.

${ }^{4} P<0.001$.

${ }^{5} P<0.001$ (infants vs mothers).

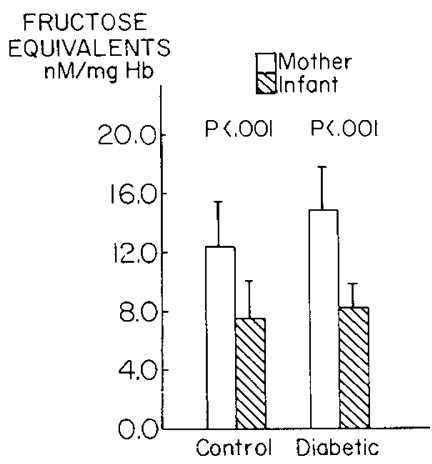

Fig. 1. Mean and standard deviation of chemically determined hemoglobin glycosylation in maternal and fetal (cord) blood at delivery of control and diabetic mothers.

diabetic mothers. In the present study, by the use of the TBA method for ketoamine linked glucose, chromatographically purified hemoglobin $\mathrm{F}$ was found to be glycosylated. The degree of glycosylation in the cord blood hemoglobin solutions and in the purified hemoglobin $\mathrm{F}$ from those solutions was similar.

The factors influencing fetal hemoglobin glycosylation are probably multiple. The approximately $15 \%$ lower plasma glucose concentration in the fetus compared to the mother can account in part for the lower total glycosylation in the newborn. In addition, 15$20 \%$ of the fetal hemoglobin is usually acetylated at the $N$-terminal amino group of the $\gamma$ chain, thus blocking glycosylation at this site $(9,20)$. Fetal red cell survival is known to be slightly decreased (13), which would decrease the duration of hemoglobin exposure to glucose. Hemoglobin structural differences (involving $N$-terminal amino acids and epsilon amino lysine groups) in fetal hemoglobin, $\alpha_{2} \gamma_{2}$, versus adult hemoglobin $\mathrm{A}_{\circ}, \alpha_{2} \beta_{2}$, may also contribute to the reduced glycosylation. It is possible that the amino groups are less exposed in the fetal hemoglobin compared to the adult hemoglobin. If fetal red cells are like those reported in adult man, cat, and dog and hemoglobin glycosylation is proportional to intracellular glucose concentration, then decreased fetal red cell membrane glucose permeability to glucose could be another contributing factor (21).

The physiologic significance of hemoglobin glycosylation in the fetus is unknown. Although hemoglobin $A_{I_{c}}$ in vitro has increased oxygen affinity, which is unaffected by 2,3 -diphosphoglycerate, it is unlikely to be significant for fetal oxygenation because fetal hemoglobin $(\mathrm{Hb} \mathrm{F})$ already has a high oxygen affinity. Inasmuch as maternal glycohemoglobin has been previously related to infant birth weight ratio $(15,23)$, the present data on fetal $\mathrm{G} \mathrm{Hb}$ and birth weight ratio is further evidence for the hyperglycemia-hyperinsulinemia hypothesis.

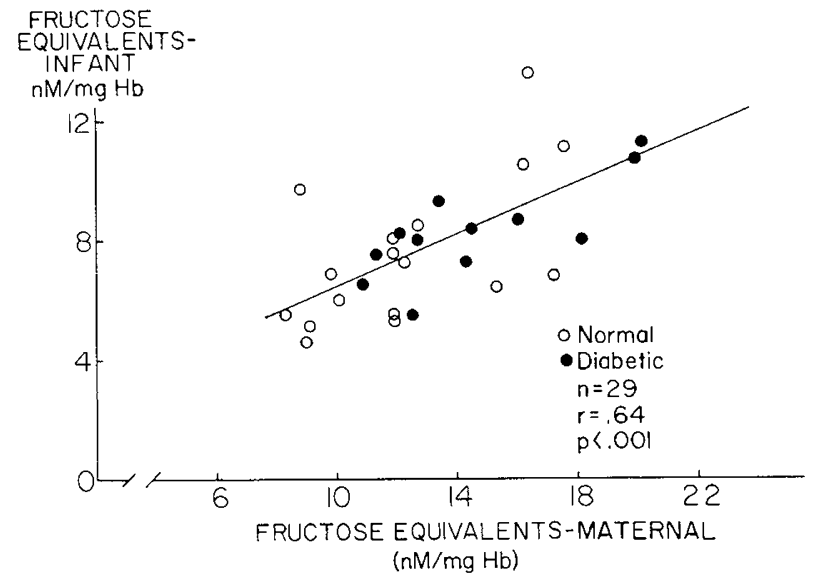

Fig. 2. The relationship of glycosylation between individual paired maternal:fetal hemoglobin samples determined by the chemical (thiobarbituric acid) method in control and diabetic subjects.

Although maternal $A_{I_{c}}$ correlated with glucose at delivery, in fact, ambient glucose over previous $4-6 \mathrm{wk}$ is likely to be a stronger influence. Under these circumstances, a weak glycosylation of "fetal $\mathrm{Hb}$ " may not be detected and, therefore, not correlate with the instantaneous plasma glucose concentration at delivery. Furthermore, the analytical variation (coefficient of variation) was higher with the TBA method compared to the HPLC technique.

Current methods for determining glycosylation of fetal hemoglobins lack sensitivity and specificity so that they are of limited practical value in assessing prior maternal glucose control. It is apparent that direct analysis of maternal blood is of greater clinical significance.

\section{REFERENCES AND NOTES}

1. Abraham, E. C.: Glycosylated minor components of human fetal hemoglobin. Biochim. Biophys. Acta, 667: 168 (1981).

2. Abraham, E. C., Cope, N.D., Brazil, N. N., and Huisman, T. H. J.: On the chromatographic heterogeneity of human fetal hemoglobin. Biochim. Biophys. Acta, 577: 159 (1979).

3. Abraham, E. C., Reese, A., Stallings, M., Garver, F. A., and Huisman, T. H. J.: An improved chromatographic procedure for quantitation of human fetal hemoglobin. Hemoglobin, 1: 547 (1977).

4. Abraham, E. C., Reese, A., Stallings, M., and Huisman, T. H. J.: Separation of human hemoglobins by DEAE cellulose chromatography using glycine-KCN$\mathrm{NaCl}$ developers. Hemoglobin, 1: 27 (1976-1977).

5. Caangay, D. L., Curran, J. S., and Malone, J. I.: Cord glycohemoglobin of infants of diabetic and non-diabetic mothers. Clin. Res., 27: 812A (1979).

6. Cornblath, M., and Schwartz, R.: Disorders of carbohydrate metabolism in infancy, 2nd Ed., p. 45. (Saunders, Philadelphia, 1976).

7. Fadel. H., Reynolds, A., Stallings, M., and Abraham, E. C.: Minor (glycosylated) 
hemoglobins in cord blood of infants of normal and diabetic mothers. Amer. J. Obs. Gynecol., 139: 397 (1981).

8. Fitzgerald, M. D. and Cauchi, M. N.: Determination of glycosylated hemoglobins in neonatal blood by isoelectric focusing. Am. J. Hematol., 9: 311 (1980).

9. Garlick, R. L., Shaeffer, J. R., Chapman, P. B., Kingston, R. E., Mazer, J. S., and Bunn, H. F.: Synthesis of acetylated human fetal hemoglobin. J. Biol. Chem., 256: 1727 (1981).

10. Haney, D. and Bunn, H. F.: Glycosylation of hemoglobin in vitro: Affinity labelling of hemoglobin by glucose-6-phosphate. Proc. Natl. Acad. Sci. USA, 73: 3534 (1976)

11. Koenig, R. J., Peterson, C. M., Kilo, C., Cerami, A., and Williamson, J. R.: Hemoglobin $A_{1}$ as an indicator of the degree of glucose intolerance in diabetes. Diabetes, 25: 230 (1976)

12. McDonald, M. J., Shapiro, R., Bleichman, M., Solway, J., and Bunn, H. F.: Glycosylated minor components of human adult hemoglobin. J. Biol. Chem., 253: 2327 (1978).

13. Oski, F and Naiman, J. L.: Hematologic problems in the newborn, p. 26. (Saunders, Philadelphia, 1972).

14. Pecoraro, R. E., Graf, R. J., Halter, J. B., Beiter, H., and Porte, D.: Comparison of a colorimetric assay for glycosylated hemoglobin with ion-exchange chromatography. Diabetes, 28: 1120 (1979).

15. Pollak, A., Widness, J. A., and Schwartz, R.: 'Minor hemoglobins': An alternative approach for evaluating glucose control in pregnancy. Biol. Neonate, 36: 185 (1979).

16. Schwartz, H. C., King, K. C., Schwartz, A. L., Edmunds, D., and Schwartz, R.: Effects of pregnancy on hemoglobin $A_{l_{1}}$ in normal, gestational diabetic and diabetic women. Diabetes, 25: 1118 (1976).

17. Schwartz, H. C., Widness, J. A., Thompson, D., Tsuboi, K. K., Oh, W., and
Schwartz, R.: Glycosylation and acetylation of hemoglobin in infants of normal and diabetic mothers. Biol. Neonate, 38: 71 (1980).

18. Skyler, J. and Cahill, G.: Diabetes mellitus: Progress and direction. Am. J. Med., 70: 101 (1981).

19. Spicer, K. M., Allen, R. C., Hallett, D., and Buse, M. C.: Synthesis of hemoglobin $A_{I_{1}}$ and related minor hemoglobins by erythrocytes. J. Clin. Invest., 64: 40 (1979).

20. Stegnik, L. D., Meyer, P. D., and Brummel, M. C.: Human fetal hemoglobin $F_{I}$. J. Biol. Chem., 246: 3001 (1977).

21. Widdas, W. F.: Transport mechanisms in the foetus. Br. Med. Bull., 17: 107 (1961).

22. Widness, J. A., Rogler-Brown, T. L., McCormick, K. L., Petzold, K. S., Susa, J. B., Schwartz, H. C., and Schwartz, R.: Rapid fluctuations in glycohemoglobin (hemoglobin $\mathrm{A}_{\mathrm{l}_{\mathrm{c}}}$ ) related to acute changes in glucose. J. Lab. Clin. Med., 95 $386(1980)$.

23. Widness, J. A., Schwartz, H. C., Edmunds, D., King, K. C., Kahn, C. B., Oh, W., and Schwartz, R.: Glycohemoglobin ( $\mathrm{Hb} \mathrm{A}_{\mathrm{t}_{\mathrm{e}}}$ ): A predictor of birth weight in infants of diabetic mothers. J. Pediatr., 92: 8 (1978).

24. Presented in part at the Annual Meeting of the Society for Pediatric Research San Francisco, CA, April 1981.

25. Requests for reprints should be addressed to: Dr. Robert Schwartz, Division of Pediatric Metabolism and Nutrition, Rhode Island Hospital, 593 Eddy Street, Providence, RI 02902, USA

26. This research was supported in part by grants from the National Institutes of Health (HD-11343, AM-25603, and RR-81), the Thrasher Fund, and the Rhode Island Hospital Research Fund.

27. Received for publication July 6, 1981.

28. Accepted for publication June 25,1982 